\title{
Observations of Thermohaline Convection adjacent to Brunt Ice Shelf
}

\author{
ILKER FER \\ Geophysical Institute, University of Bergen, Bergen, Norway \\ KeITH MaKinson AND KeITH W. NichOlls \\ British Antarctic Survey, Cambridge, United Kingdom
}

(Manuscript received 16 November 2011, in final form 2 January 2012)

\begin{abstract}
Observations were made of ocean microstructure and horizontal currents adjacent to Brunt Ice Shelf in the southeastern Weddell Sea. Periods of in situ supercooled water extending as deep as $65 \mathrm{~m}$ were associated with ice nucleation and frazil formation at depth. Ascending ice crystals due to convection lead to increased dissipation rates. The main outflow of potentially supercooled water from deep beneath ice shelf is suggested to be in the deep channel northeast of the measurement site. Because this water is advected southward along the front, it becomes in situ supercooled, leading to suspended ice formation, thermohaline convection, and enhanced dissipation.
\end{abstract}

\section{Introduction}

\section{a. Motivation}

Melting at the base of Antarctic ice shelves affects the oceanographic conditions of the Antarctic continental shelf and, in some sectors, contributes to the production of Antarctic Bottom Water (AABW). Changes in basal melting that result, for example, from iceberg calving events or a varying local climate also lead to changes in the geometry of the ice shelf and the restraint it provides on the flow of grounded inland ice into the ice shelf, with consequences for global sea level (Payne et al. 2004). Because of the global reach of the issues of AABW production and sea level change, the focus of recent research into the interaction between ice shelves and the Southern Ocean has been on those processes thought to have the potential to change ice shelf geometry or to affect $\mathrm{AABW}$ production: that is, melting deep within the cavity where the difference between the pressuredependent freezing point and the inflowing water tends to be greatest, leading to the highest melt rates.

Processes that have received comparatively little study are those in the vicinity of the ice front. Here, summer warming of the water column, coupled with

Corresponding author address: Ilker Fer, Geophysical Institute, University of Bergen, Allegaten 70, Bergen N-5007, Norway.

E-mail: ilker.fer@gfi.uib.no tidal advection beneath the ice shelf, can lead to high rates of seasonal melting (Jenkins 1991), affecting the summertime oceanography of the continental shelf and the draft of icebergs that periodically calve. Another icefront process involves ice shelf water (ISW), water from deep beneath the ice shelf that has been chilled by contact with the deep ice base. ISW is potentially supercooled: that is, cooled below the surface freezing point. If it rises toward the surface when it flows out from beneath the ice shelf it can become in situ supercooled. The production of ice crystals that results can cause a form of convection (Foldvik and Kvinge 1974), and the ice so produced can contribute to the local sea ice budget (Bombosch 1998) and the local ecology (Dieckmann et al. 1986).

First microstructure profile observations from adjacent to an ice shelf suggest that the small-scale turbulent energetics in McMurdo Sound can influence the formation and aggregation of frazil ice crystals within a near surface supercooled layer (Stevens et al. 2009). More recently, Stevens et al. (2011) presented a series of microstructure profiles from fast ice near Erebus Glacier Tongue in the Ross Sea showing that floating glacier tongue leads to flow accelerations and increased levels of turbulence, influencing the oceanic mixing and transport processes. To study processes at an ice front, we conducted an experiment from a ship moored to fast ice, some $200 \mathrm{~m}$ from Brunt Ice Shelf, in the southern 

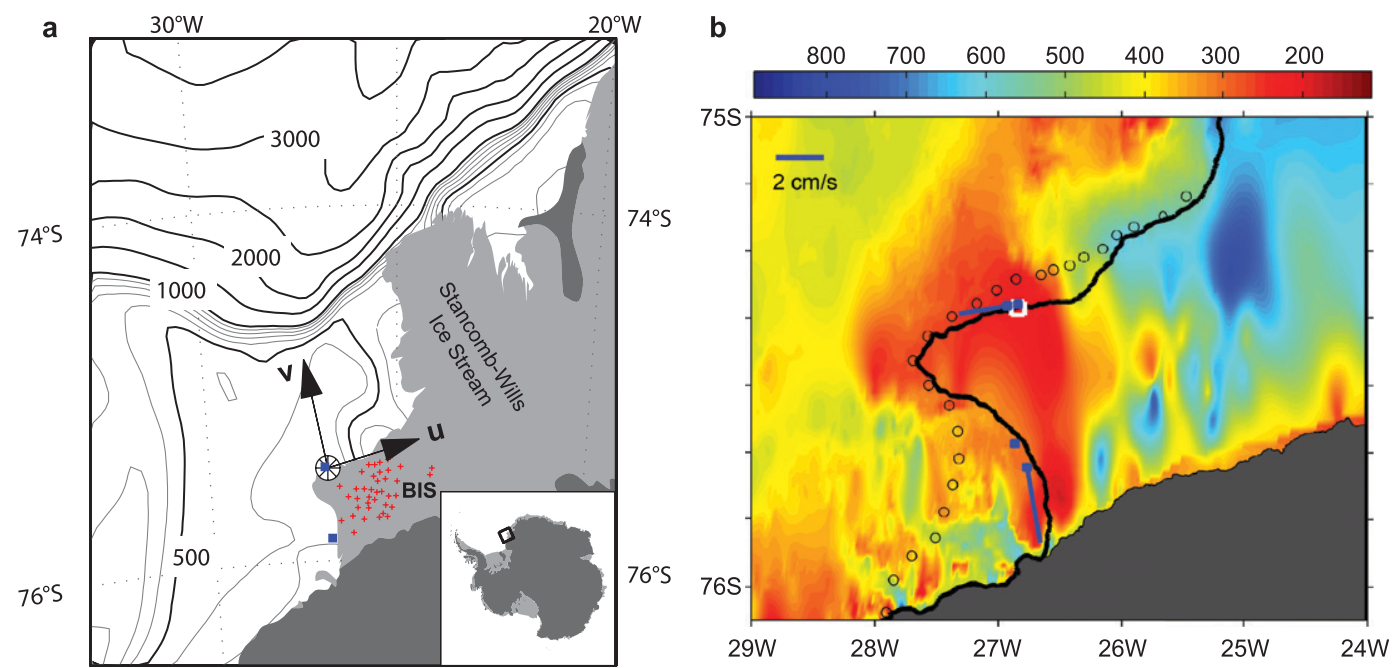

FIG. 1. (a) Location of the station occupied at the Brunt Ice Shelf front together with the rotated coordinate system. Bathymetric contours are drawn at 500-m intervals to 500-m depth and 100-m intervals for shallower depth using the bed topography of the Antarctic (BEDMAP; Lythe and Vaughan 2001). Areas shaded in light gray are ice shelves; those in dark gray are land (Antarctic ice cap). Also shown are the seismic sites (red crosses) and mooring positions (blue squares). The inset shows the location of the shown region. (b) Map showing the bathymetry at the study site including that beneath the ice shelf inferred from the seismic sites. Locations of CTD stations (circles); mooring locations (blue squares); and the experiment site (white square) are also shown. Both moorings were displaced by icebergs; both the deployment and recovery locations are shown, with the latter including the 2-yr mean velocity vectors at $40 \mathrm{~m}$ height above bottom recorded by the moored current meters.

Weddell Sea. The aim of the experiment was to study the water column properties and their evolution over a few tidal cycles using a ship-mounted acoustic Doppler current profiler (ADCP), a conductivity-temperaturedepth (CTD) profiler, and a vertical microstructure profiler (VMP).

\section{b. Brunt Ice Shelf}

Brunt Ice Shelf (Fig. 1) is the westernmost of the eastern Weddell Sea ice shelves (EWIS), which overlie a narrow continental shelf to the east of the large southwestern Weddell Sea embayment that is home to the Filchner-Ronne Ice Shelf. The continental slope of the EWIS is washed by the westward-flowing southern limb of the Weddell Gyre. Here, this takes the form of a shelfbreak front current, coupled with a nearby coastaltype current that has been observed flowing along the ice fronts (Nicholls et al. 2009).

The ice shelf thickness ranges from about $260 \mathrm{~m}$ at the grounding line to as little as $100 \mathrm{~m}$ at its western tip. Along the northwest ice front, where the experiment was conducted, the ice is around $140 \mathrm{~m}$ thick. The bathymetry beneath the ice shelf and the flow structure between the ice shelf front and the sampling location are poorly known. The bathymetry shown in Fig. 1b uses a combination of ship-derived ice-front data, grounding line ice thickness data, and spot measurements across the ice shelf from 43 seismic sites. The main feature is the steep east-west slope beneath the eastern portion of the ice shelf, associated with a shoal farther west.

Figure $1 \mathrm{~b}$ shows the locations of a CTD section that was occupied in February 2007. The sections of potential temperature $\theta$ and salinity $S$ indicate an inflow of $-1.87^{\circ} \mathrm{C}$ eastern shelf water (ESW) into the western side of the trough associated with Stancomb-Wills Ice Stream, and a northward outflow of $-1.99^{\circ} \mathrm{C}$ ISW along the western flank of the trough, at around $26.5^{\circ} \mathrm{W}$ (Fig. 2). Datasets from the current meters (2003-05; positions shown in Fig. 1) indicate a mean flow of around $2-5 \mathrm{~cm} \mathrm{~s}^{-1}$ along the ice front, presumably drawing the ISW with it to yield the distribution shown in the $\theta$ section. The absence of outflowing ISW at the southwestern ice front suggests that any flow transiting beneath the ice shelf from the northeast to the southwest is relatively weak, consistent with the shoal in the bathymetry shown in Fig. 1b.

\section{Measurements and data}

Measurements were made between 19 and 22 February 2009 at $75^{\circ} 28.5^{\prime} \mathrm{S}, 26^{\circ} 50.5^{\prime} \mathrm{W}$ from the RSS Ernest Shackleton while she was moored to fast ice near Brunt 


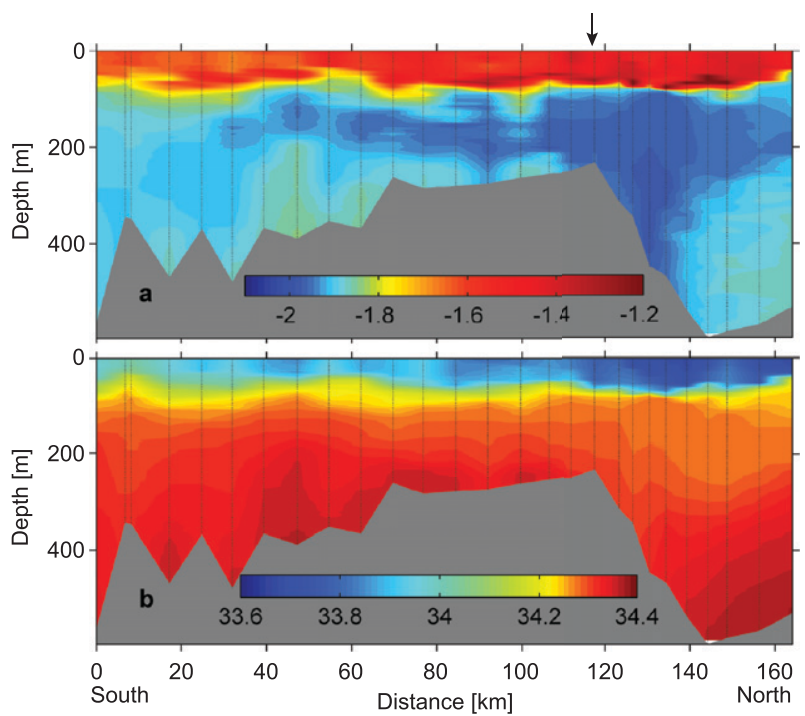

FIG. 2. Contours of (a) potential temperature and (b) salinity along the CTD section occupied in February 2007 (see Fig. 1b for station locations). The arrow on top marks the approximate location of the experiment station occupied in 2009.

Ice Shelf during a logistics visit to Halley Research Station. Profiles of hydrography and microstructure were collected by repeatedly deploying the VMP (Rockland Scientific International). Profiles of ocean current were sampled using an RD Instruments Longranger ADCP. At this location, the water depth was $217 \mathrm{~m}$ and the ice shelf draft was about $100 \mathrm{~m}$.

Profiles were collected approximately $3 \mathrm{~m}$ from thick fast ice and some $200 \mathrm{~m}$ from the ice front. A series of casts was made, one every $15-30 \mathrm{~min}$, at a nominal fall rate of about $0.6 \mathrm{~m} \mathrm{~s}^{-1}$ from the surface to $7 \mathrm{~m}$ above the seabed. The sampling was interrupted for $8.5 \mathrm{~h}$ between 1340 and 2210 UTC 20 February 2009, when the cable had to be reterminated. In addition to tilt sensors, accelerometers and a Kelley pressure transducer in the main pressure case, the VMP was fitted with two air-foil shear probes, one FP07 fast thermistor and a Sea-Bird SBE7 microconductivity probe for turbulence measurements, and a pair of pumped Sea-Bird SBE-3 temperature and SBE-4 conductivity sensors for precision CTD measurements.

The ADCP was set to average ensembles of 120 continuous profiles at 5-min intervals (i.e., $2.5 \mathrm{~s}$ between pings) with an $8-\mathrm{m}$ vertical bin size. The horizontal velocity error was less than $0.2 \mathrm{~cm} \mathrm{~s}^{-1}$. The ADCP was suspended from the aft of the vessel, about $4 \mathrm{~m}$ from the VMP deployment location, with transducers about $2 \mathrm{~m}$ below the surface. The center of the first bin was at about $14 \mathrm{~m}$. Good quality data were recovered for 46.3-h duration starting from 1810 UTC 19 February 2009.

\section{Data processing methods}

\section{a. Microstructure data processing}

The dissipation rate of turbulent kinetic energy (TKE) was calculated using the isotropic relation $\varepsilon=7.5 \nu\left\langle u_{z}^{\prime 2}\right\rangle$, where $\nu$ is the viscosity of seawater. Small-scale shear variance $\left\langle u_{z}^{\prime 2}\right\rangle$ was obtained by iteratively integrating the low wavenumber portion of the shear spectrum of halfoverlapping 2-s segments (Fer 2006). Unresolved shear variance in the noise-affected high wavenumber portions was corrected using the empirical theoretical shape (Oakey 1982). The profiles of $\varepsilon$ were produced as 1-m vertical averages to a noise level of $10^{-10} \mathrm{~W} \mathrm{~kg}^{-1}$.

\section{b. ADCP data processing}

The ADCP data were flagged when the percentage of good three- and four-beam solutions was less than 50 or the relative error (the ratio of the horizontal speed to its standard error) was less than 0.5 . Remaining spikes in the velocity time series were detected and flagged. The portions with gaps of less than 1-h duration (12 ensembles) were interpolated.

The ADCP transmits sound at a $76.8-\mathrm{kHz}$ frequency and detects echoes returning from sound scatterers in the water. The water-mass volume backscattering strength $S_{v}$ (in units of $\mathrm{dB}$ ) is calculated using the sonar equation in Deines [1999, Eq. (2)], which gives the received energy as a function of the energy emitted and that lost due to absorption and beam spreading along the twoway path of the sound. Increased echo intensity (signal strength) measured by the instrument, typically as a result of increased scatterer concentration in the water column, leads to an increase in $S_{v}$.

\section{c. Tides}

Tidal velocity components were predicted from the Circum-Antarctic Tidal Simulation (CATS; updated version 2008b) inverse barotropic tide model (Padman et al. 2002). The north component of the tidal velocity is shown in Fig. 3a (the east component is comparable and varies within $\pm 8.5 \mathrm{~cm} \mathrm{~s}^{-1}$ : i.e., $75 \%$ of the north component) together with the tidal ellipse for the dominant $M_{2}$ constituent (Fig. 3b). The CATS prediction agrees with the depth-averaged current measured by the ADCP and suggests that measurements were made during transition to spring tides. Current ellipses inferred from the $M_{2}$ constituent (CATS and harmonic analysis of the ADCP time series) are oblique to the orientation of the ice front (Fig. 3b); that is, there is significant along-ice-front component.

\section{Results and discussion}

The site is dominated by the presence of ISW, although relatively fresh, warm water appears in the upper 

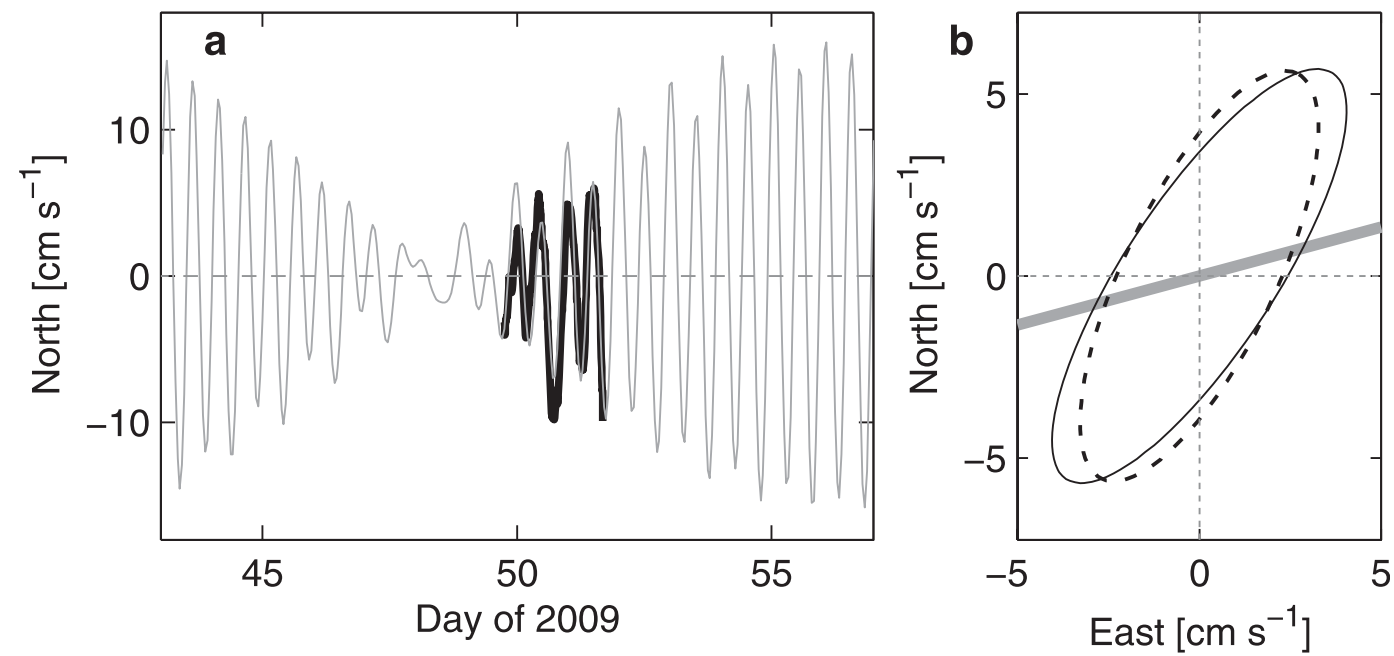

FIG. 3. (a) Time series of the north component of the current. The gray line is the tidal current inferred from CATS at the location of the station, and the thick black line is the depth-averaged ADCP measurements smoothed over $12 \mathrm{~h}$. (b) Current ellipses inferred from the $M_{2}$ component from CATS (solid line) and the $M_{2}$ component from harmonic analysis of the ADCP data (dashed). The thick gray line shows the orientation of the ice front.

$80 \mathrm{~m}$ during the first and last $\sim 6 \mathrm{~h}$ of the record (Fig. $4 \mathrm{a}$ ). Following a significant uplift of isopycnals between days 50 and 50.2 , the upper $50 \mathrm{~m}$ is in situ supercooled, persisting until day 51.68, when the upper layer is restratified by the warmer and less saline surface water. The maximum supercooling of $0.044 \mathrm{~K}$ occurred near the surface at day 51.35; for the following $1.1 \mathrm{~h}$ (in four consecutive casts) supercooling extended to as deep as $65 \mathrm{~m}$ with values $(1-5) \times 10^{-3} \mathrm{~K}$. For a one-hour period centered at day 51.3, the ADCP data show backscattering intensity increasing by $10-25 \mathrm{~dB}$ down to $62-\mathrm{m}$ depth (Fig. 4f). The correspondence with the in situ supercooled water suggests that the $S_{v}$ anomaly is associated with ice nucleation and frazil formation at depth.

A mechanism was proposed by Foldvik and Kvinge (1974) in which the formation of ice crystals in ascending ISW might result in a type of conditional convective instability. This happens when the cold ISW at depth is displaced upward to become in situ supercooled, leading to the formation of small ice crystals. The most direct evidence of the phenomenon is visual observations made by the authors of ice crystals ascending to the surface. Such observations were made (logged and photographed) in at least two periods, for several hours, at days 50.6 and 51.3. These periods agree with the increases in backscattering intensity shown in Fig. 4f. During the first period, when the frazil formation was most intense (as judged from the $S_{v}$ record), there were no VMP data. A comparison between the concurrent VMP and ADCP data, however, shows that the period of strongly increased backscattering strength is associated with the presence of ISW, anomalies reaching about $20 \mathrm{~dB}$ for temperatures below $-1.9^{\circ} \mathrm{C}$ (Fig. 5).

The dissipation rate $\varepsilon$ time series shows large variability (Fig. 4c), increasing by up to four orders of magnitude above the noise level. The quiescent region is primarily located below the base of the ice front, with the exception of relatively enhanced dissipation rates in the bottom boundary (note that deepest dissipation measurement is about $7 \mathrm{~m}$ above the seabed). The variability and elevated values of $\varepsilon$ in the upper half of the water column cannot be explained by wind stress (the weather was calm throughout the experiment) or by tidal straining (Simpson and Bowers 1981; the observed average dissipation rate is estimated to be at least one order of magnitude greater than the buoyancy flux induced by tidal straining). The increased dissipation rates, however, are not always associated with an increase in $S_{v}$ : for example, between days 50.3 and 50.5 and between days 50.9 and 51.1. During these periods, the 8-m Richardson number Ri (i.e., density gradient and velocity shear calculated at $8-\mathrm{m}$ vertical intervals) varies between 0.4 and 1.5 when averaged in the upper $100 \mathrm{~m}$, suggesting that the mean shear can contribute to generation of TKE. Between days 51.2 and 51.4, on the other hand, when both $\varepsilon$ and $S_{v}$ are elevated, Ri is significantly above unity $(\mathrm{Ri}=3.5)$. We hypothesize that the formation of the ice crystals cause instability, which then leads to convection and increased dissipation rates. Our data show that the dissipation rate significantly increases, by more than one order of magnitude, when in situ supercooling occurs (Fig. 6). 


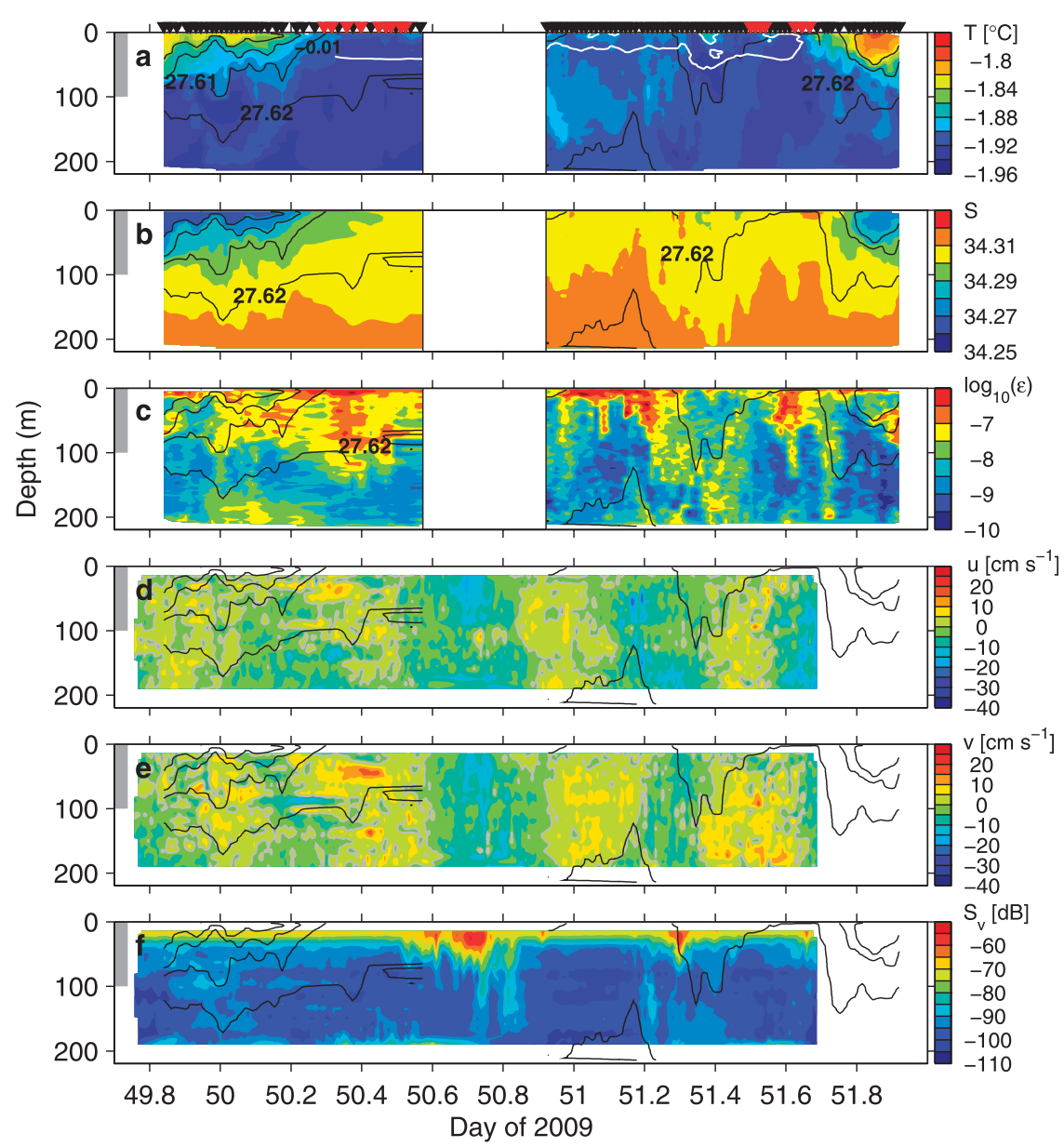

FIG. 4. Contour plots of (a) temperature; (b) salinity; (c) dissipation rate of TKE ( $\varepsilon$ ) measured by the VMP; and (d) along-ice-front $(u)$, (e) across-ice-front ( $v$; positive out of ice shelf), and (f) backscattering intensity $\left(S_{v}\right)$ measured by the Longranger ADCP. Contours of $\sigma_{\theta}$ are overlaid at 0.01 unit intervals in black. The gray contours in (d) and (e) are $u=v=0$. Temperature below in situ freezing point is indicated by the white $-0.01-\mathrm{K}$ contour in (a). Each VMP cast is marked by a triangle at the top; those with a suspicious conductivity (hence salinity and density) signal indicating large overturns are marked in red and excluded from the analysis. The vertical gray bar on the left approximates the vertical extent of the ice front.

In the absence of shear production of TKE, when the production is solely due to convection, the dissipation rate is $60 \%-70 \%$ of the convection-favorable buoyancy flux $B$ and scales with the convective vertical velocity $w_{*}=(D B)^{1 / 3}$, where $D$ is the depth over which convection occurs (Shay and Gregg 1984). For $T-T_{f}<0$ (22391-m segments), $\varepsilon=1.7( \pm 3.4) \times 10^{-7} \mathrm{~W} \mathrm{~kg}^{-1}$. For $D=50 \mathrm{~m}$, the typical vertical extent of the supercooled region, $w_{*}$ is about $2 \mathrm{~cm} \mathrm{~s}^{-1}$. This is comparable to frazil rise velocities summarized in McGuinness et al. (2009). The buoyancy flux of about $2 \times 10^{-7} \mathrm{~W} \mathrm{~kg}^{-1}$ is about 4 times that observed in the unstable oceanic boundary layer under Arctic leads during modest surface fluxes (McPhee and Stanton 1996).
The flow evolution between the ice shelf front and the sampling location is unknown and might affect our interpretation of the data; the banded velocity structure at middepth, for example, can be related to blocking processes because of the presence of the shelf. During periods of strong outflow, one might expect more ISW ascending in front of the ice shelf and therefore more ice formation and dissipation due to induced convection. Time series of $u$ and $v$, averaged over bins between 20 and $94 \mathrm{~m}$ (upper layer: subscript 1) and deeper than $94 \mathrm{~m}$ (lower layer: subscript 2) were interpolated to VMP cast times and correlated with $\varepsilon$ averaged in the same layers. For periods of significant outflow in the lower layer $\left(v_{2}>1 \mathrm{~cm} \mathrm{~s}^{-1}: 57\right.$ data points), $v_{2}$ does not 


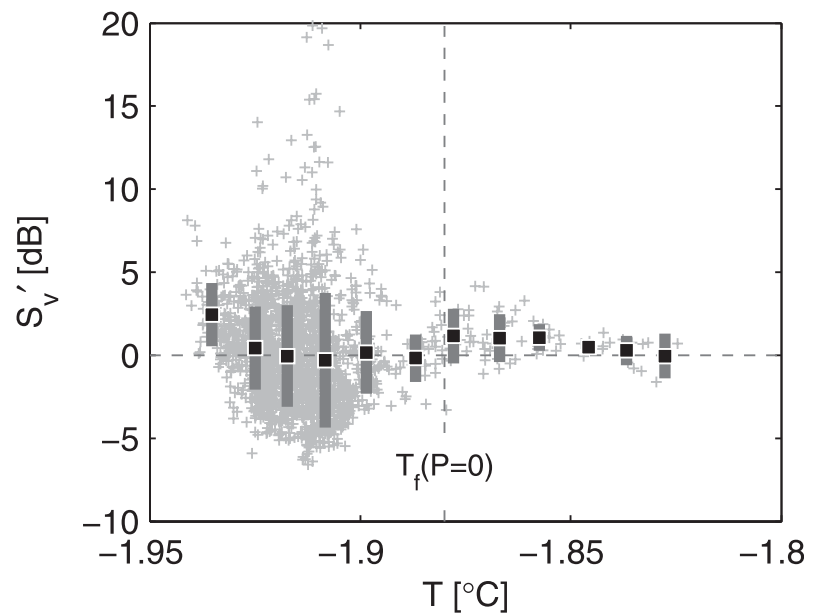

FIG. 5. Backscattering strength anomaly $S_{v}^{\prime}$ variability with water temperature. To use the datasets measured by the ADCP and the VMP, the ADCP data are 30-min averaged and then interpolated to times of VMP casts, and VMP profiles are 8-m vertically averaged at the corresponding ADCP bins. Here, $S_{v}^{\prime}$ is calculated by removing the time average at each bin. Gray crosses show individual $8-\mathrm{m}$ data points. Averages (squares) in $0.01^{\circ} \mathrm{C}$ bins together with one standard deviation are shown. The vertical dashed line marks the surface freezing point and delineates the ISW from relatively warmer water.

lead to an increase in the average dissipation in the upper layer $\varepsilon_{1}$. The scatter is large and there is even a small negative correlation (correlation coefficient $r=0.28$ ). The data points for the times with strong westward flow along the ice front from the deep channel farther east (i.e., $u_{2}<-1 \mathrm{~cm} \mathrm{~s}^{-1}$ ) show a strong correlation with $\varepsilon_{1}$ $(r=0.4)$. All correlation coefficients are significant at 97\%. These results, together with the CTD section shown in Fig. 2, indicate that the main outflow of ISW occurs in the deep channel east of the measurement site. As this water is advected westward along the front, it ascends the seabed slope and becomes in situ supercooled, leading to ice formation, thermohaline convection, and enhanced dissipation.

Our observations provide direct evidence for enhanced dissipation rates associated with the conditional thermohaline convection mechanism proposed by Foldvik and Kvinge (1974). The ice crystal formation at depth and its ascent to the surface will influence the local sea ice budget and contribute to underwater ice production. Upwelling of the water associated with the convection might supply nutrients from the bottom layer toward the euphotic zone and enhance the primary production. The formation of ice crystals in suspension is probably a characteristic feature of the ice shelves producing ISW in the Southern Ocean and constitute an additional source of TKE production, which might increase mixing

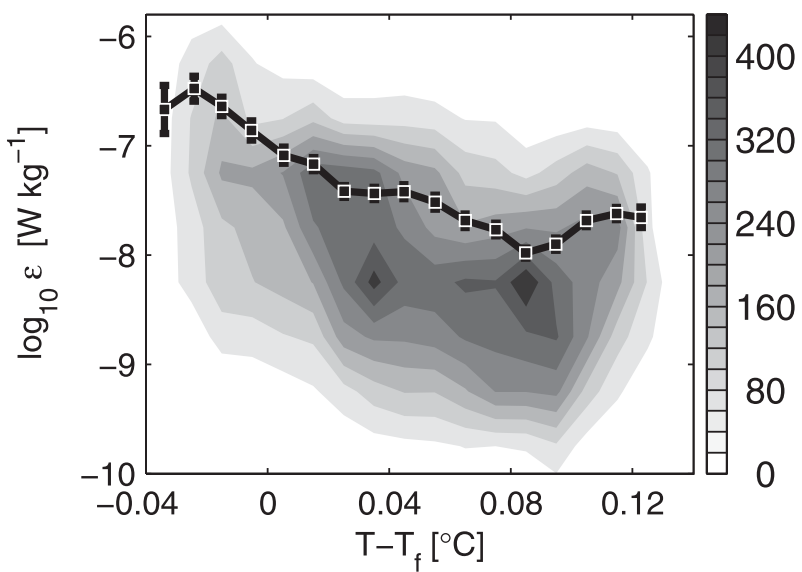

FIG. 6. The 10-base logarithm of the dissipation rate $\varepsilon$ vs the temperature above in situ freezing point $T_{f}$. The gray contours show the 2D histogram using all 1-m data points (17 759 in total) with the color bar showing the number of data points in $0.01-\mathrm{K}$ temperature and half-decade $\varepsilon$ bins. Maximum likelihood estimator from a lognormal distribution (squares) and $95 \%$ confidence intervals (error bars) are shown for 0.01-K bins.

substantially with consequences for the regional stratification and circulation.

Acknowledgments. The authors thank the officers, crew, and engineers of RRS Ernest Shackleton for their support and John Beaton, Helge Bryhni, Cedric Chavanne, Kjersti L. Daae, Colin Griffiths, and Bruce Huber for their assistance in collecting the data. Povl Abrahamsen helped with Fig. 1b, and Colin Griffiths supplied the Longranger for the experiment.

\section{REFERENCES}

Bombosch, A., 1998: Interactions between floating ice platelets and ocean water in the southern Weddell Sea. Ocean, Ice, and Atmosphere: Interactions at the Antarctic Continental Margin, S. S. Jacobs and R. Weiss, Eds., Amer. Geophys. Union, 257266.

Deines, K. L., 1999: Backscatter estimation using broadband acoustic Doppler current profilers. Proc. Sixth Working Conf. on Current Measurement, San Diego, CA, IEEE, 249-253.

Dieckmann, G. S., H. Hellmer, and J. Kipfstuhl, 1986: The occurrence of ice platelets at $250 \mathrm{~m}$ depth near the Filchner Ice Shelf and its significance for sea ice biology. Deep-Sea Res., 33A, 141-148.

Fer, I., 2006: Scaling turbulent dissipation in an Arctic fjord. DeepSea Res. II, 53, 77-95.

Foldvik, A., and T. Kvinge, 1974: Conditional instability of seawater at freezing-point. Deep-Sea Res., 21, 169-174.

Jenkins, A., 1991: A one-dimensional model of ice shelf-ocean interaction. J. Geophys. Res., 96C, 20 671-20 677.

Lythe, M. B., and D. G. Vaughan, 2001: BEDMAP: A new ice thickness and subglacial topographic model of Antarctica. J. Geophys. Res., 106B, 11 335-11 351. 
McGuinness, M. J., M. J. M. Williams, P. J. Langhorne, C. Purdie, and J. Crook, 2009: Frazil deposition under growing sea ice. J. Geophys. Res., 114, C07014, doi:10.1029/2007JC004414.

McPhee, M. G., and T. P. Stanton, 1996: Turbulence in the statically unstable oceanic boundary layer under Arctic leads. J. Geophys. Res., 101C, 6409-6428.

Nicholls, K. W., S. Østerhus, K. Makinson, T. Gammelsrød, and E. Fahrbach, 2009: Ice-ocean processes over the continental shelf of the southern Weddell Sea, Antarctica: A review. Rev. Geophys., 47, RG3003, doi:10.1029/2007RG000250.

Oakey, N. S., 1982: Determination of the rate of dissipation of turbulent energy from simultaneous temperature and velocity shear microstructure measurements. J. Phys. Oceanogr., 12, 256-271.

Padman, L., H. A. Fricker, R. Coleman, S. Howard, and L. Erofeeva, 2002: A new tide model for the Antarctic ice shelves and seas. Ann. Glaciol., 34, 247-254.
Payne, A. J., A. Vieli, A. P. Shepherd, D. J. Wingham, and E. Rignot, 2004: Recent dramatic thinning of largest West Antarctic ice stream triggered by oceans. Geophys. Res. Lett., 31, L23401, doi:10.1029/2004GL021284.

Shay, T. J., and M. C. Gregg, 1984: Turbulence in an oceanic convective mixed layer. Nature, 310, 282-285.

Simpson, J. H., and D. Bowers, 1981: Models of stratification and frontal movement in shelf seas. Deep-Sea Res., $\mathbf{2 8 A}$, 727-738.

Stevens, C. L., N. J. Robinson, M. J. M. Williams, and T. G. Haskell, 2009: Observations of turbulence beneath sea ice in southern McMurdo Sound, Antarctica. Ocean Sci., 5, 435445.

C. L. Stewart, N. J. Robinson, M. J. M. Williams, and T. G. Haskell, 2011: Flow and mixing near a glacier tongue: A pilot study. Ocean Sci., 7, 293-304, doi:10.5194/os-7-293-2011. 